\title{
Sensory expectations elicited by the sounds of opening the packaging and pouring a beverage
}

\author{
Charles Spence ${ }^{*}$ and Qian (Janice) Wang
}

\begin{abstract}
The majority of the literature on sensory expectations has focused solely on those that are set by the eye, that is, by what we see. However, although we rarely think about it, the sounds we hear prior to tasting also influence both our sensory expectations concerning what a food or beverage product will taste like and our hedonic expectations concerning how much we think that we are going to enjoy the experience. In this article, we focus on the perception of beverages and consider just what information is potentially conveyed to the mind of the consumer by the sounds of opening (the packaging), pouring the liquid, and even the sounds of carbonation of a drink in a glass or other receptacle. We review the research that has investigated whether people can discriminate the temperature of a beverage, the level and/or type of carbonation, the viscosity of the liquid, and even the shape of the bottle or container by sound alone. Finally, we look at the question of whether certain beverages do, or could possibly, have a signature sound of opening, and at the opportunities associated with the modification of product sounds in beverage advertisements in order to help emphasize certain specific product or brand attributes.
\end{abstract}

Keywords: Sensory expectations, Opening sounds, Pouring sounds, Carbonation sounds, Sonic branding, Sensory marketing, Advertising

\section{Background}

To date, the majority of the literature on sensory expectations has focused on those expectations that are set by what we see, be it the colour, sheen, or texture of food or drink (see [1] for a recent review; see also [2]). It is, however, important to note that the sounds that we hear prior to tasting can also influence both our sensory expectations concerning what a food or beverage product will taste like and our hedonic expectations concerning how much we think that we are going to enjoy the experience [3]. In this article, we focus on the perception of beverages and consider just what information is potentially being conveyed to the consumer's brain by the sounds of opening (the packaging), the sounds of pouring, and even by the sounds of carbonation as a drink is held in a glass or other receptacle. We review the claims that have been made, and the experimental data that has

\footnotetext{
*Correspondence: charles.spence@psy.ox.ac.uk

Crossmodal Research Laboratory, Department of Experimental Psychology, South Parks Road, Oxford OX1 3UD, UK
}

been collected, concerning whether people can discriminate the temperature, carbonation and/or viscosity of a drink simply by listening to the sounds that it makes when opened and/or poured. We examine the role that the shape of the bottle or container plays in constraining the pouring sounds that are heard. To close, we address the question of whether certain beverages do currently, or could one day in the future, have a signature sound of opening (or, for that matter, pouring), a sound that consumers would immediately associate with a particular brand, say. Finally, we look at some of the opportunities around the modification of product sounds in advertisements, namely sounds that have been designed to help emphasize certain product attributes or brand values. Taken together, the evidence suggests that there is more information in beverage sounds than is often realized.

\section{Sensory marketing}

Given the huge amounts of money that is spent year-onyear on distinguishing brands visually, it seems peculiar that nearly every canned or bottled drink sounds the 
same on opening or pouring [3]. Perhaps it is the case that different brands of drink really do sound (a little) different when opened or poured, but few marketers have thus far attempted to draw their consumers' attention to this fact. This seems like a lost opportunity for marketing and multisensory product design. Things are, however, slowly starting to change. There has been an explosive growth of interest in sensory marketing and sensory branding over the last decade [4-8]. Ultimately, as Doug Hall, the president of one new-product development company notes: "...the most successful new products appeal on both rational and emotional levels to as many senses as possible." ([9], p. 22; see also [10, 11]). The suggestion from some practitioners is that strong brands need to be recognizable by as many senses as possible and in nearly every case that includes a sonic touch-point [7]. According to Krishna ([12], p. 332), sensory marketing can be defined as "marketing that engages the consumers' senses and affects their perception, judgment and behaviour."

\section{Auditory product/packaging design}

Over the last few years, the topic of audio or sonic branding has become increasingly popular [13-15]. While much of the interest here has been on the development of catchy jingles and auditory logos, some of those working in the field are especially interested in the sounds of products and our interaction with them [16-18]. This area of research, then, intersects with the field of psychoacoustics or auditory product design [19-21]. One of the aims for those working in this field should be to develop signature sounds (that is, product sounds or product interaction sounds) that are distinctive $[5,7,16])$ and which convey some functional benefit in terms of the consumer's product experience or brand impression [18]. While consumers typically deny that sound plays any role in their product experience, the empirical data clearly suggests otherwise [22]. For instance, Spence and Zampini [23] demonstrated that the sound of an aerosol spray could be manipulated (by making it louder or by boosting just those sounds in the $2-20 \mathrm{kHz}$ range) in order to make the product appear more forceful and pleasant. Elsewhere, Knöferle [24, 25] modified the sound of a capsule coffee maker and demonstrated that those participants hearing the modified coffee machine sound rated their coffee differently than another group of participants who tasted the same coffee after having heard the unadulterated machine sound instead.

That such ideas around sonic/audio design are being taken seriously by those working in the fast-moving consumer goods (FMCG), and Home and Personal Care (HPC) categories are evidenced by products such as the Lynx/Axe deodorant can, whose novel twist and spray nozzle design, inspired by Spence and Zampini's [23] sonic design findings, can now be found on supermarket shelves around the world. Or take the debacle of a few years ago around Sun Chips (see [26], pp. 126-127; [18]). Frito-Lay introduced a new biodegradable form of packaging for their product in 2010. However, it was so noisy, coming in at over $100 \mathrm{~dB}$ when gently held and rattled, that the company were soon forced to withdraw it from the shelves $[16,27]$. Surely, it can be no coincidence that such a noisy form of packaging, which was certainly distinctive, and most-definitely attention capturing, was paired with a food that is itself fairly noisy. In fact, from the very beginning when potato chips were first packaged, the marketers apparently immediately realized that it would be a good idea to put such a noisy product in packaging that was itself noisy [28]. The right packing sound can enhance the consumer's perception of the contents [29].

\section{Beverage product sounds: just how much information do they contain?}

In this article, the focus is on the perception of beverages and on the sensory and hedonic expectations that the consumer's interaction with them gives rise to. We start by looking at the information that beverage sounds might provide. We compare the (generally unsubstantiated) claims of sensory experts that one occasionally comes across in the literature [30] with the results of rigorously controlled laboratory (and increasingly, online) research [31, 32]. Furthermore, we look at what has previously, what is currently, and what might in the future potentially be done in terms of enhancing the sounds that are associated with our interaction with beverages and the packaging in which they are presented (to the consumer). This is currently an exciting area for research and development, one that the marketers have been predicting will be huge for a number of years now (e.g. [7], pp. 200-201). At the end, we will see how a new generation of augmented glassware is now opening up a range of exciting possibilities in terms of the sounds that we may all be listening to while we drink in the future. We also outline a number of areas for future research.

\section{The sound of opening}

Although beverage packaging undoubtedly makes some sound when we pick it up, ${ }^{1}$ the most noticeable sound of our interaction normally comes when the consumer opens the packaging, be it a pressurized can or bottle. One of the most famous examples of a distinctive packaging opening sound is the "Snapple Pop" (see Fig. 1). According to the Snapple (owned by Dr Pepper Snapple Group Inc.), the pop that the consumer hears on unscrewing the cap from an unopened bottle provides a 


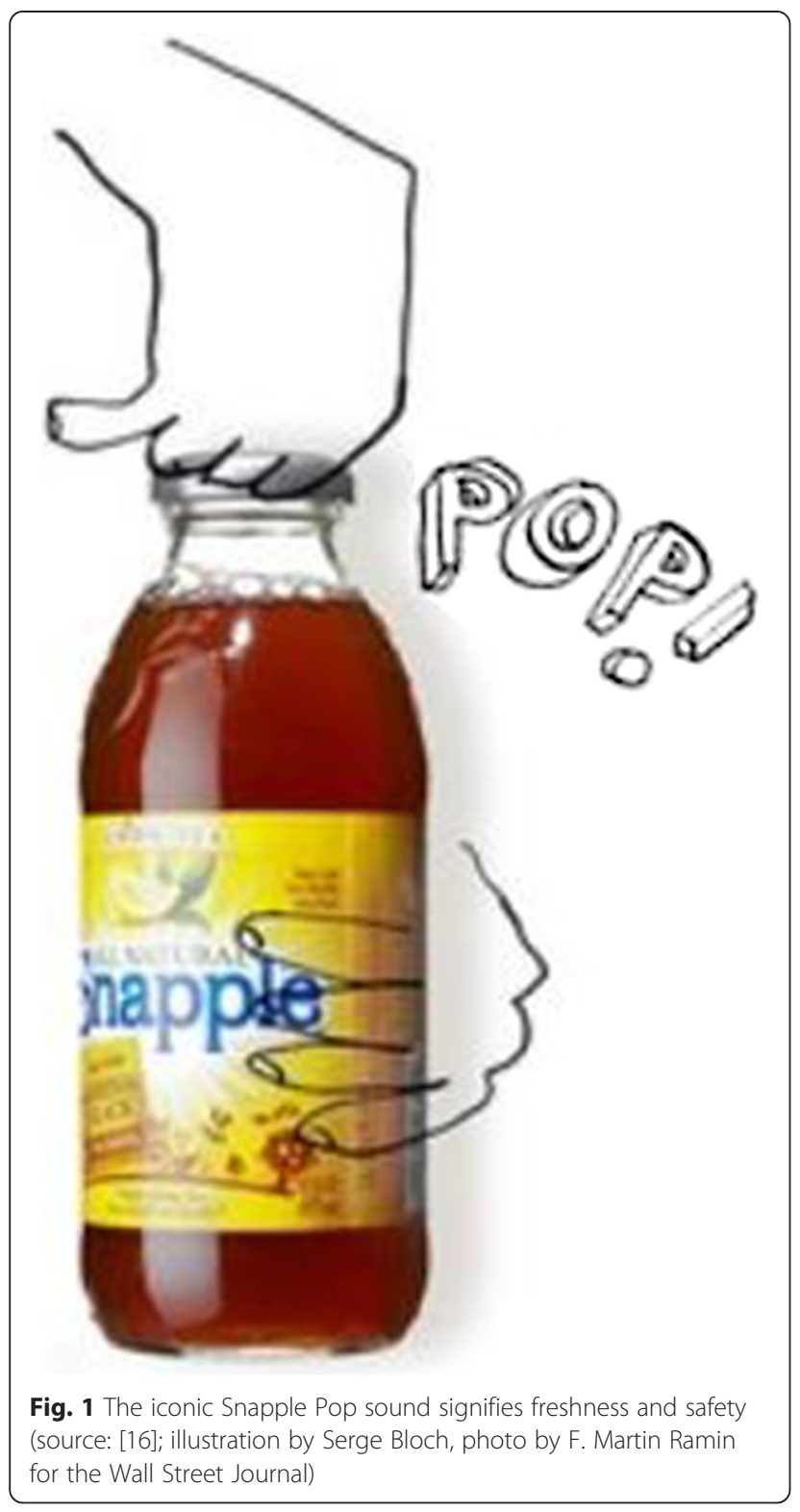

cue to freshness. "The company calls it the "Snapple Pop". They believe that it builds anticipation and offers a sense of security, because the consumer knows the drink hasn't been opened before or tampered with." [16]. ${ }^{2}$

Another type of bottle opening sound that many consumers suggest might be sonically distinctive is generated by the Grolsch flip-top or swing-top beer bottle (see https://www.youtube.com/watch? $\mathrm{v}=8$ IASnim-6u 8 ). ${ }^{3}$ It can be argued that both Snapple and Groslch have managed to create a point of sonic differentiation from the competitors in the marketplace. Furthermore, the Snapple Pop also has the functional benefit to the consumer of signalling that the product is fresh and has not been tampered with. However, beyond these two popular examples, it is hard to think of (m)any other distinctive branded beverage opening sounds. Some individuals are convinced that they can tell the difference between cans of Coke and Pepsi (see https://www.facebook.com/ pages/The-sound-when-opening-a-cold-can-of-coke/245 057948305), based on nothing more than their supposedly distinctive opening sounds. As yet, however, we have not been able to track down any evidence relevant to assessing this claim empirically. Beyond any distinctive "signature" properties of an opening sound, one might wonder what other information the sounds that are associated with the opening of a can, say, might convey to the consumer. Can people, for instance, tell anything about the level of carbonation in a drink? Is it possible to tell (or discriminate) the temperature of a drink from the sound that the can or bottle makes when first opened (or when reopened)? Certainly, for a product that the consumer is familiar with, one could imagine that hot and cold drinks might sound different enough for people to be able to tell when the container is initially opened. There are a number of factors here that might influence the sound that a pressurized drink can makes on opening. The gauge of the metal used in the can's construction, for example, might play a role [19]. Here, one might wonder whether a steel can of Sapporo, for example, sounds different from that of other aluminium canned beers [33]?

\section{Pouring sounds}

Perhaps, the richest part of our interaction with a beverage, at least sonically speaking, comes when a drink is poured from the packaging into some form of receptacle or drinking vessel. There will, for example, be information concerning the presence and level/type of carbonation. More surprisingly, there is also information concerning the temperature of the liquid.

\section{The sound of temperature}

Having opened the can or bottle, one might wonder whether the consumer can tell anything about the temperature simply from the sound the liquid makes when poured into a glass or mug, say. That at least is the claim that one finds in the literature [26]: "On the basis of sound alone, we are able to distinguish clean water from dirty water and cold beer from warm beer. Its temperature can be recognized from the sound produced when fluids hit on a surface, for instance, on the floor of a beer glass. Warm beer sounds hollow and lifeless, cold beer, by contrast, bright and crisp." ([30], p. 104). More specifically, as the temperature of a liquid changes, so too does its viscosity, and hence the pitch of the sound that it gives off when poured from one container into another [34]. Interestingly, though, when we asked 60 people, less than half of them thought that 
they would be able to discriminate hot from cold liquid pouring sounds [31].

We recently tested the ability of regular consumers to tell the difference between hot and cold liquid pouring sounds in a series of experiments conducted in the lab, online, and at various science festivals around the UK $[31,32]$. Initially, the sounds of water being poured into cups of different materials such as glass, porcelain, and paper were recorded. The water in this case came either from a kettle that had just been boiled or else from a jug of water that had been sitting for a while in the fridge (82-84 ${ }^{\circ} \mathrm{C}$ or $6-8{ }^{\circ} \mathrm{C}$, respectively). These sound files were then played back to a group of participants who answered more than $70 \%$ of their forced choice decisions correct when it came to discriminating between the sound of hot and cold water. Subsequently, when we repeated the experiment with more than 100 people at the 2013 Edinburgh Science Festival, essentially the same pattern of results was obtained (see Fig. 2). Thus, people can clearly tell whether a drink is hot or cold simply based on pouring sounds. The evidence also shows that people are unaware that they can do this.

\section{The sound of carbonation}

Vickers ([35], p. 95) suggested that the sounds of "fizziness" produced by certain fine champagnes might have particular characteristics, such as higher pitched fizz produced by the smaller bubbles. Lawless ([36] p. 93) made a similar point: "I often think I can tell something about the quality of a fine champagne by listening to the fizz. Many small bubbles give off a higher pitched fizz than the gross clumpy fat bubbles of a club soda". That the carbonation sounds associated with the beer in a glass are equally, if not more, informative is hinted by Stummerer and Hablesreiter's ([30], p. 105) suggestion that "The finale of the sound composition is the foam crown that rises up

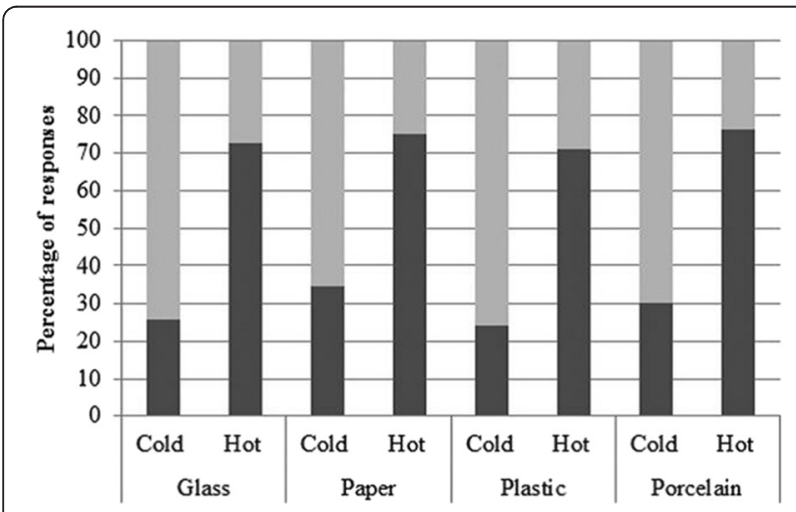

Fig. 2 Results of a recent study by Velasco et al. [32] demonstrating that people can discriminate whether a liquid is hot or cold on the basis of the auditory cues that can be heard when a drink is poured into a glass. Performance, while by no means perfect, is certainly much better than chance. (Figure reprinted with permission from [32].) with an unbelievably fine and diverse texture of sounds. Any connoisseur is, for instance, able to distinguish light beer from dark beer." Stummerer and Hablesreiter suggest (though without providing any empirical evidence) that acoustically trained individuals can distinguish up to 100 different brands of beer simply by listening to the sound of the liquid when the glass is being filled (assuming, that is, that the temperature of the beers is held constant).

We recently demonstrated that normal individuals can discriminate between the carbonation sounds associated with different beverages when poured into a glass (see Table 1 for a summary of the results). The 71 participants (see [37], for details) performed at a level that was significantly better than chance when discriminating between the sounds of San Pellegrino sparkling water (43/71), Pisani prosecco (37/71), and Tattinger NV champagne (44/71) each being poured into a champagne flute. In this case, the participants heard the entire set of pouring sounds a couple of times before having to make their choices (possibly making the task a little easier than it might otherwise have been.

In another study, 12 out of 35 professionals working with/in the alcohol industry correctly identified the sound of champagne (although 21 mislabelled the champagne sound as prosecco), 30/35 correctly identified sparkling water, and 20/35 correctly identified prosecco (although a further 12 guessed champagne). These results demonstrate that at least those working in the alcohol industry can discriminate sparkling water from sparkling wine. In a separate online study, 31 participants listened to the sounds of sparkling water, prosecco, and champagne being poured into both a champagne flute and a water glass. On each trial, the participants were presented with three sounds (either pouring into the flute or into the glass) and were asked to match the sounds with three possible liquids (sparkling water, prosecco, and champagne). A chi-square test of independence was conducted to assess whether the container into which the liquids were poured influenced participants' matching of the sounds with the liquids, but no significant effect was obtained $\left(X^{2}(8357)=6.48\right.$, $p=.59$ ). Of the 119 responses, 63 correctly identified the sparkling water, 45 correctly identified the prosecco, and 53 correctly identified the sounds of champagne. The participants' performance for sparkling water and champagne was significantly better than chance $\left(X^{2}=22.40, \quad p<.0005\right.$, and 9.19, $p=.010$, respectively).

Even the sound of carbonation in a drink that has already been poured can provide useful information. For example, Zampini and Spence [38] conducted a series of experiments to demonstrate that the perceived (or rated) carbonation of a cup of sparkling water that was held in the hand could be modified simply by boosting either 
Table 1 Results from multiple sparkling sound tests, shown as percent of participants who made a given choice for each sound

\begin{tabular}{|c|c|c|c|c|c|c|c|c|c|c|}
\hline & & Live ev & $=64)$ & & Live ev & $=35)$ & & Online & $=31)$ & \\
\hline & & Choice & water, $\mathrm{P}$ & $\overline{\operatorname{secco}, C}$ & mpagne & & & & & \\
\hline & & $\bar{W}$ & $P$ & C & W & $P$ & $C$ & W & $P$ & C \\
\hline Sounds & W & $61 \%{ }^{*}$ & $31 \%$ & $8 \%$ & $86 \%^{*}$ & $11 \%$ & $3 \%$ & $53 \%^{*}$ & $29 \%$ & $18 \%$ \\
\hline & $P$ & $25 \%$ & $52 \%^{*}$ & $23 \%$ & $9 \%$ & $34 \%$ & $57 \%$ & $26 \%$ & $38 \%$ & $36 \%$ \\
\hline & C & $23 \%$ & $15 \%$ & $62 \% *$ & $6 \%$ & $60 \%$ & $34 \%$ & $22 \%$ & $34 \%$ & $45 \% *$ \\
\hline
\end{tabular}

Italicized numbers denote correct choices. Asterisks denote correct choices that are significantly different from chance $(p<.05)$

the loudness of the popping sounds (boosting sounds in the $2-20 \mathrm{kHz}$ range by $20 \mathrm{~dB}$ ) or the speed at which the bubbles were heard to pop in the cup (see Fig. 3).

\section{The sound of viscosity}

Anecdotally, it has been suggested that the viscosity of a liquid is audible. At the extreme, of course, this must be true-think only of the sound of pouring water versus honey (see also [39], pp. 15-17). However, for more comparable liquids, think water, wine, versus something like cognac, one might ask whether any difference in pouring sounds be perceptible. We recently tested people's ability to discriminate between liquids of different viscosities at London's Science Museum Cravings exhibit, as part of a citizen science experiment. Participants could either access the experiment at the gallery or on-line, via the Science Museum's homepage or the Cravings exhibition information page (http://www. sciencemuseum.org.uk/visitmuseum/Plan_your_visit/ex hibitions/cravings/cravings-experiment.aspx). The participants typically heard one of three pouring sounds, associated with water, water with $25 \%$ sugar by weight added and water with $50 \%$ sugar by weight added, and had to rate on two seven-point scales how "thick and sticky" (with 7 being most sticky) and how pleasant the pouring sounds were. In this case, people were unable to discriminate the difference in viscosity based on sound alone. ${ }^{4}$ It should, though, be borne in mind here that people mostly only heard one of the three sounds in isolation. ${ }^{5}$ Had they been able to compare the sounds, performance might have been somewhat better.

Another example of sound viscosity is manifest in alcohol levels, as liquids with a lower alcohol content are less viscous than liquids with a higher alcohol content. The question here, then, is whether people can discriminate the sound of white wine being poured from the sound of red being poured. We recently investigated whether people could hear any difference between the sounds of a low-alcohol white wine (Tesco's Vinho Verde 2013, 9 \% alcohol) and a high-alcohol red wine (Ridgy-Didge Shiraz 2012, $14.5 \%$ alcohol) being poured into both white and red wine glasses. In an online test $(N=43)$, where the participants had to answer four questions (testing the sounds of pouring into both red

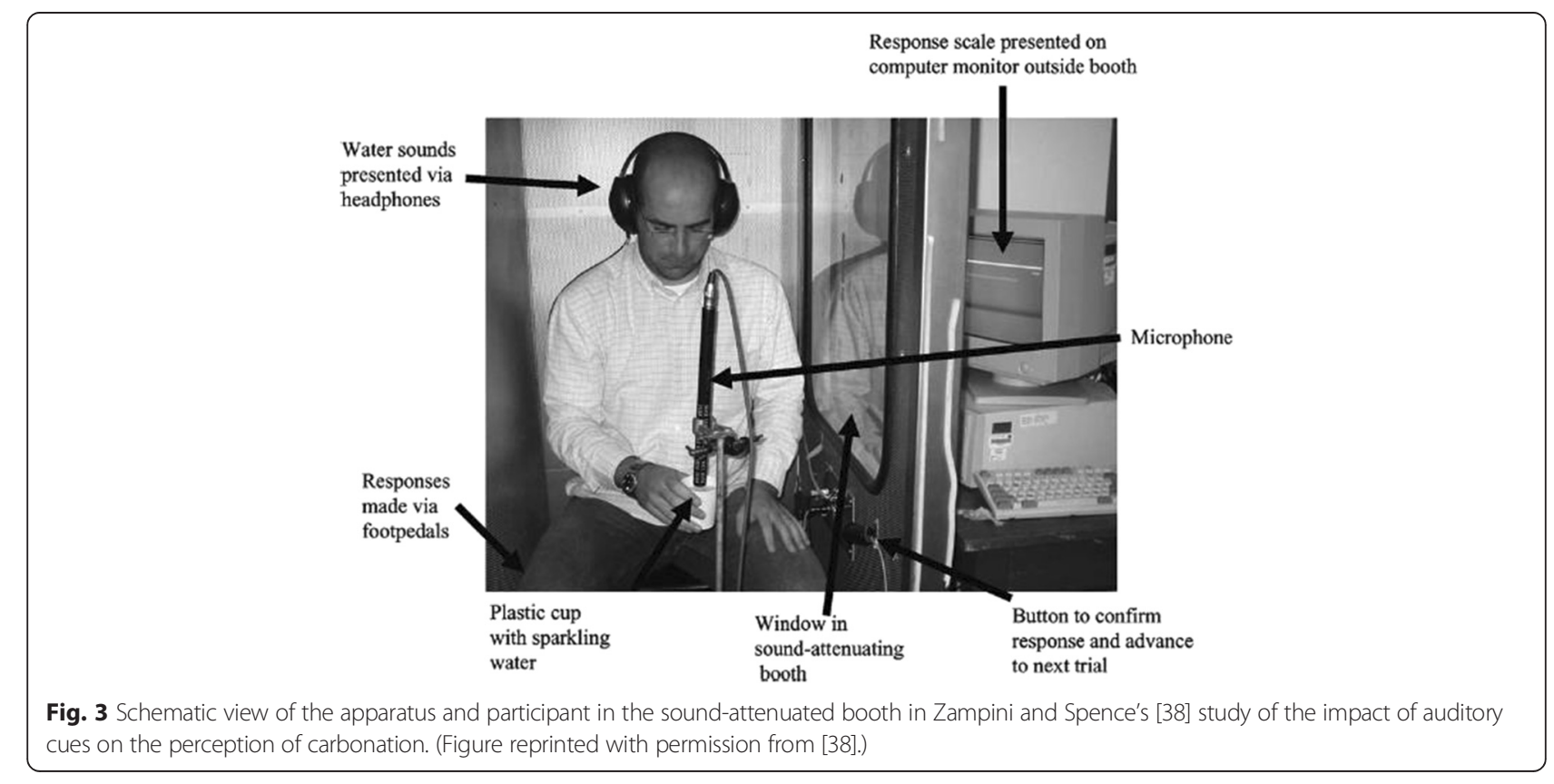


and white wine glasses, with both orders of sound presentation), performance was significantly better than chance. The participants answered more questions correctly $(99 / 172)$ than expected by chance $(86 / 172)$, $X^{2}(1172)=3.930, p=.047$. Once again, a chi-square test of independence revealed there was no significant association between the type of wine glass that the wines were poured into (white or red wine glass) and the participants' performance $X^{2}(1172)=.595, p=.440$.

\section{On the sound of the bottle and glass}

Not only do we hear the sound of the liquid as it comes into contact with the glass or receptacle, we also hear the periodic sound as air makes its way into the bottle to equalize the air pressure. Smith ([40], p. 53) makes the intriguing suggestion that expensive wines generate a distinctive gentle glugging sound when poured from the bottle (see also [41]). Certainly, one could imagine how the temporal dynamics of the sound of wine being poured from a broad-shouldered Bordeaux bottle would differ from the sound of a similar wine poured from a sloping-shouldered Burgundy bottle, or even a taller, narrower, Riesling bottle (see Fig. 4).

According to Friedrich Blutner, an eminent psychoacoustician (cited in [30], p. 105): “...The sounds that beer makes can be influenced by the composition of the drink on the one hand and by the shape of the bottle on the other hand. Clever breweries design the bottleneck-consciously or intuitively-so that a striking gurgling sound between 5 and 6 hertz is produced when the beer is poured." ... "The rhythm of 5 to 6 hertz makes us happy and a beer which gurgles from the bottle in this rhythm simply sounds happy." The elongated narrow

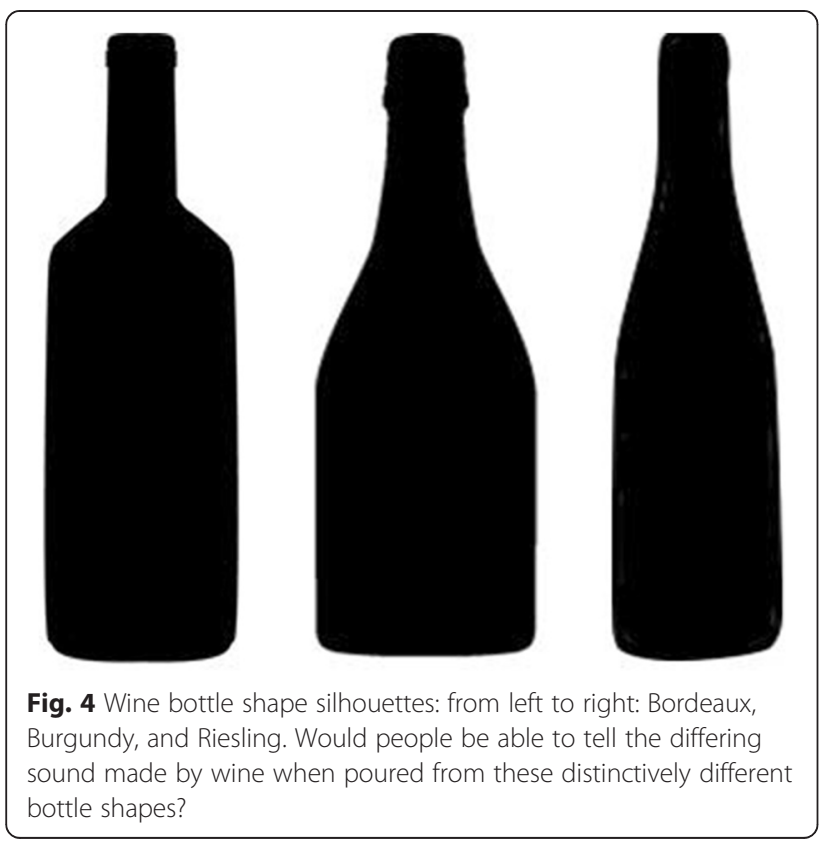

neck of the Beck's beer bottle was apparently chosen for just this reason.

Elsewhere in the literature, one finds researchers showing that sighted blindfolded individuals are also pretty good at filling a receptacle to the brim based on sound alone [42]. ${ }^{6}$ Listeners can, one presumes, pick up information concerning fundamental resonant frequency that increases as a cylindrical vessel fills. ${ }^{7}$ Given such intriguing results, one might also wonder whether people could tell the shape of the glass into which a drink was poured. The results reported so far would seem to argue against this possibility. It is, though perhaps worth noting that in all of the studies that have been mentioned so far, more than one factor was varied at once, i.e. both the shape of the glass and the liquid being poured. As such, the dominant sound cue might have driven the choices that our participants made.

Therefore, in order to assess whether, when all of the other factors are held constant, people can hear the shape of the glass (or at least discriminate between different glass shapes), at the Somerville event mentioned earlier, the sounds of water being poured into a white wine glass and the sound of the same liquid now being poured into a red wine glass were played. Under these conditions, performance turned out to be significantly worse than chance $(27 / 70$ and $28 / 70$, respectively, for white wine glass and red wine glass), according to the results of a one-tailed test of significance. ${ }^{8}$ These results suggest that people can perhaps discriminate between the sounds made when liquids are poured into different glasses, but they just misattribute the pouring sounds to the respective glasses that they have been given to choose between. ${ }^{9}$ However, given the preliminary nature of this study, it would certainly be worth following up with more thorough psychophysical testing before coming to any firm conclusions regarding people's ability to discern anything about glass shape from auditory cues.

\section{Interim summary}

Taken together, while certain of the more extravagant claims that one finds in the literature have found no support, the evidence that has been reviewed in this section demonstrates that the sounds of beverage opening and pouring, even the sound of the carbonated beverage sitting in a drinking vessel, provide information concerning the physical properties of a drink (in terms of the temperature and level of carbonation). Of course, having demonstrated an audible difference between different branded beverage sounds, the question is whether that difference can be linked to brand values/attributes (see the "Advertising product sound" section). Many of the results that have been outlined in this section are consistent with JJ Gibson's [43, 44] early notion of affordances, that is, the structured aspects of 
environmental auditory stimulation that potentially provides information to the listener $[19,39,45]$.

\section{Caveats and limitations}

Do the sensory and hedonic expectations that are elicited by the sounds of out interaction with a beverage influence our subsequent experience when we actually come to drink? While the visual expectation literature provides robust support for such a claim [1], one of the few attempts to look at this question in the domain of beverage perception failed to demonstrate any influence of modified carbonation sounds on people's perception of carbonation once a drink had been taken into the mouth [38]. However, that said, the sound manipulation had little ecological validity. Hence, different results might well have been obtained had the sonic manipulation been more realistic. Distinctive beverage sounds can presumably influence taste/flavour perception as a result of associative learning: Just remember Pavlov's dogs salivating in response to the sound of the bell that preceded feeding [46, 47]. The distinctive sound of opening of a specific brand of beverage packaging might elicit some sort of salivatory response in humans as well, especially if that signature opening sound happened to be associated with an especially sour or acidic drink (see [48], for a review of the literature on salivation). ${ }^{10}$

A second key issue that needs further investigation here relates to the fact that the majority of research on auditory design has been conducted under conditions where all other sensory cues relating to the drinks under consideration have been removed. Note that while it is one thing to say that we can tell the temperature of a drink from the sound when that is the only cue that we are exposed to, it is obviously quite another to show that such information is used/available when other sensory cues are available (such as vision and/or touch). After all, we are all visually dominant creatures $[18,49]$, and the psychology/neuroscience literature is replete with demonstrations showing that what is seen dominates or fundamentally changes what is heard $[19,50,51] .^{11}$

A final concern here relates to the fact that the majority of experiments in this area have understandably been performed under those conditions in which all background noise has been eliminated. Once again, this is most unlike the conditions of everyday life [52]. Hence, while much of the research reported here clearly shows that sonic cues provide useful information under quiet laboratory conditions, it is less clear that such sounds will necessarily be audible to those who are drinking in bars and restaurants, where the background noise levels can exceed $100 \mathrm{~dB}$ (see [52] for a review). ${ }^{12}$

\section{Advertising product sound}

Is it anything more than merely an urban myth that Coke had a sound designer engineer the sound of their can opening in the ads of old? Did Unilever really emphasize the sound of the cracking as the model bit into the chocolate coating of their Magnum ice cream on the screen [18]? Certainly, over the last few decades, there have been some great examples of the advertisers capitalizing on the distinctive sound of their food products in the advertisements that they have brought to market. Just think, for those who are old enough, of "Snap, Crackle, Pop" (Kellogg's Rice Krispies) and "Plop Plop Fizz Fizz" (Alka-Seltzer; [16]). Once upon a time, there was even an ad for 7-Up in which the opening sound of the can changed a warm sunny environment into a cool and fresh, rainy place [53].

Ultimately, though, the question that we are concerned with in this article is whether any physical differences in the signature sound of a beverage can be linked to some kind of consumer benefit. If a can sounds colder on opening, can the consumer be convinced that the drink would more likely be refreshing, if it were to be consumed? Interesting in the context of product sounds in adverts, we have recently demonstrated that it is possible to create caricatured hot and cold liquid pouring sounds (see [32], experiment 3). Just like visual caricaturizations of characters in newspaper cartoons, where some features like ears and noses are accentuated to highlight their distinctive features, we did the same with the design of pouring sounds. That is, one can compare the sounds of hot and cold drinks being poured and then look for those regions of the frequency spectrum that differ between the two. One can then take the original hot sound and caricature (filter) it to make it sound "hotter than hot" and vice versa for the cold sound to make something that potentially sounds colder-thancold (or super-refreshing, say). ${ }^{13}$

The participants in Velasco et al.'s [32] study correctly spotted the coldest pouring sound $64 \%$ of the time, the cold sound they got right on $54 \%$ of the trials, the hot sound was identified correctly $49 \%$ of the time, and finally the hottest sound $83 \%$ of the time (all of these were significantly higher than chance level performance which would have been $25 \%$ correct; see Fig. 5). Given such intriguing results, one might think about extending this approach in order to see whether the sounds of opening could also be manipulated in order to give the listener the impression of a drink that was especially carbonated or perhaps especially cold (assuming that these are desirable beverage characteristics amongst the subset of the population that a marketer is interested in; cf. [54]). ${ }^{14}$ Coca Cola in Brazil recently launched an interesting ad that played with the sound of the drink being poured over ice (see also [55]. As McMains [55] puts it: 


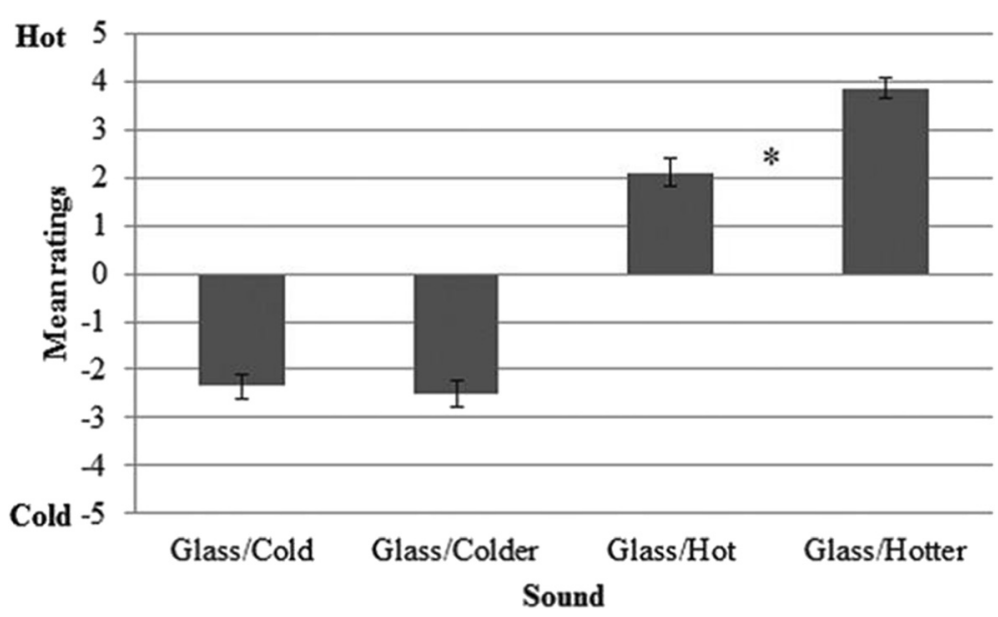

Fig. 5 Mean temperature ratings for the hot and cold liquids and for the artificially modified versions of these sounds developed and tested by Velasco et al. [32]. The error bars show the standard errors of the means. The hot liquids were rated as significantly different from one another $\left({ }^{*} \leq .001\right)$. (Figure reprinted with permission from [32].)

"When it comes to creating the sensation of being inside a Coca-Cola while it's being poured over ice, sound is everything." Although outside of the scope of the present manuscript, it is worth drawing attention to the related literature on the modification of product sounds in order to create a more luxurious (lighter) sound [56].

One beer manufacturer recognized the potential problem of the change to the sound of their packaging. Specifically, when Carlsberg introduced a new plastic beer bottle, focus groups commented extensively on the changed sound of bottle opening. A special advertising campaign was then launched in order "to prepare customers for the change in sound and tactile feeling" (see [7], pp. 107-108). The focus of the campaign was presumably quite different from that of the glass producer in Colombia who, last year, created a series of ads that played on the sound of glass bottles (see the Vidrio es vida campaign by Peldar, highlighting the sonic benefits of glass bottles over other beverage packaging materials; see https://www.youtube.com/watch?v=pQAcY8oee5Y). Along similar lines, a few years ago, an unnamed beer manufacturer tried to elicit the sound of quality by varying the hiss that was heard when their cans of beer were opened ([57], p. 108). One final example of the use of distinctive pouring sounds in advertisements comes from a campaign for Brahma beer in Brazil. According to Roberts ([58], pp. 211-212), a campaign was created around the "Tss" sound of opening of the beer. The campaign was so successful that Brazilians could order a beer in a bar simply by making the Tss sound. According to Roberts, the sound became an icon in its own right.

\section{Augmented beverage sounds}

Another company who has been working to emphasize the distinctive sound of their beverage's carbonation is
Krug champagne. Back in 2012, they tasked French designer Ionna Vautran with developing a shell-shaped listening device (see Fig. 6) specifically "designed to amplify the sounds of the spirits' bubbles to create a new sensation for drinkers." [59]. In other words, consumers were invited to listen in a more mindful way to the sounds of the bubbles/mousse. ${ }^{15}$ In the years to come, it will be interesting to see whether it might also be possible to enhance the sound of carbonation through digitally augmented glassware. Indeed, we are already starting to see the arrival in the marketplace of the first drinking vessels that have been augmented to allow sound or music to be heard from within (e.g. see [60] for one recent example). ${ }^{16}$ The idea of augmenting the serviceware in order to bring back the sound of the fizz of the tonic was also considered by Denis Martin for his modernist take on the "Gin \& Sonic," which due to the use of liberal amounts of liquid nitrogen, lost its sound of fizz [61].

\section{Conclusions}

As this review of the burgeoning literature on auditory product design (psychoacoustics; [19]) and sonic branding (a key component of any comprehensive multisensory marketing strategy; $[62,63])$ has hopefully made clear, there is currently a real lost opportunity in terms of distinguishing branded drinks on the basis of the sounds they make when cans, bottles, or other beverage packaging formats are opened. Ludden and Schifferstein [64] demonstrated that the sound made by a product contributes to what people think about the product itself. As we have seen throughout this piece, though, the potential for product/brand differentiation does not stop with the sound of opening. Pouring sounds also convey information about the temperature of a drink and its 

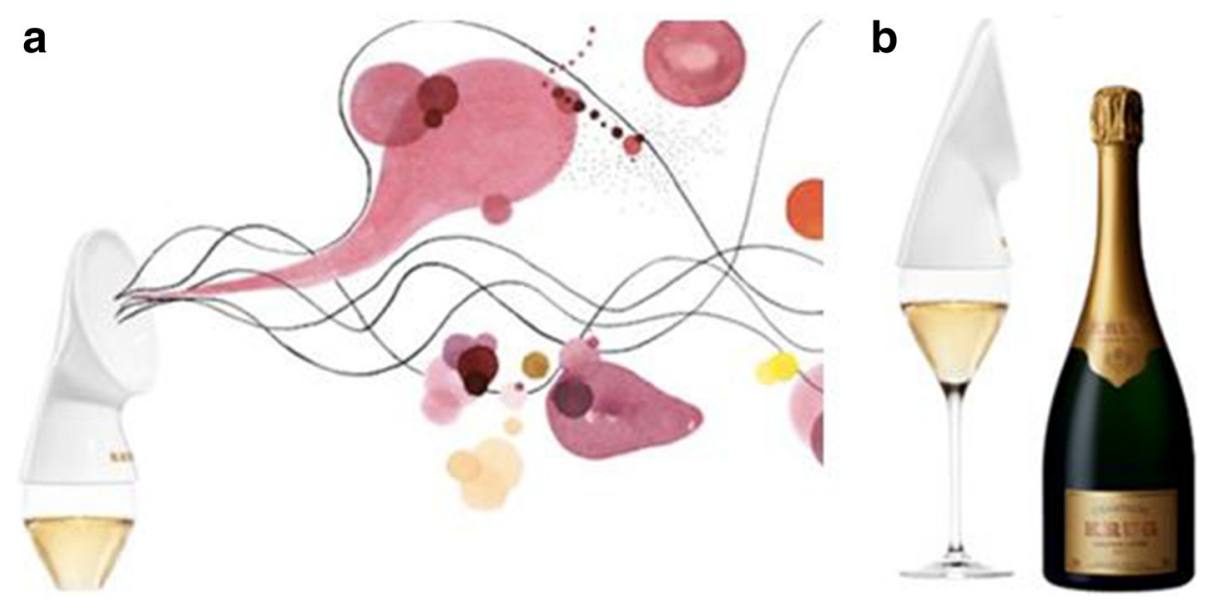

Fig. 6 a The Krug shell is designed by French artist lonna Vautrin to enhance, or amplify, the sound of the bubbles popping in a glass of Krug champagne. b The Krug Shell on top of a Joseph glass with a bottle of Krug Grande Cuvée (photos from Krug's A Journey of Emotions Web site section and reprinted in [59].)

level/type of carbonation [31, 32]. It has even been suggested, though as yet without the supporting evidence, that a particular bottle shapes can deliver especially pleasing sounds $[30,40]$. While in none of the cases that we have looked at have listeners been perfect in terms of discriminating the meaning (or association) of the opening and pouring sounds that they have listened to, they have nevertheless been significantly better than chance. Presumably, the ultimate mark of success in the world of sonic branding, or auditory product design, is when a company tries to protect the distinctive sound of its product-here, just think of Harley Davidson's attempt to protect the sound of their motorcycle exhaust ([7], pp. 108-109; [65-67]) or a little more relevant in the present context, Kellogg's attempt, some years back, to try and protect the distinctive sound that their cereals made when milk was added in the bowl ([7], p. 12). ${ }^{17}$

There are still a number of open questions regarding future research on the sonic expectations elicited by the sound of opening beverage packaging and pouring. While it is clear that people can hear the difference between drinks of differing temperature, carbonation, and to a certain degree viscosity, what has yet to be convincingly established is whether such sonic expectations can influence people's judgments of the sensory properties of a drink. Future research will also need to determine just how distinctive opening sounds can be made, and whether under the noisy conditions of everyday life, such sounds, when associated with a specific brand, can influence people's hedonic ratings of the product.

\section{Ethics}

The collection of the data reported in this article was approved by the Central University Research Ethics
Committee of Oxford University under MSD-IDRECC1-2014-205 (how music affects the perception of food and drink) and MSD-IDREC-C1-2014-198 (how sound communicates information about the multisensory environment).

\section{Endnotes}

${ }^{1}$ Note that the inquisitive shopper will sometimes shake product packaging in order to get a sense of how full, or thick/viscous the contents are ([61], p. 213). Here, think only of the difference in sound that a liquid packaged in Brik versus Tetra Pak makes when agitated gently.

${ }^{2}$ According to Byron [16]: "Snapple was so confident about the pop's safety message that in 2009 , it eliminated the plastic wrapping that encircled the lid. It saved on packaging costs and eliminated an estimated 180 million linear feet of plastic waste, the company says. "We were a lot more comfortable making that decision because we knew there was this iconic pop," says Andrew Springate, senior vice president of marketing."

${ }^{3}$ This type of closure used to be frequently used for bottles that contained a carbonated beverage, such as beer or mineral water. The mouth of the bottle is sealed by a stopper, traditionally made of porcelain or increasingly of plastic, fitted with a rubber O-ring, and held in place by wires (adapted from https://en.wikipedia.org/ wiki/Flip-top).

${ }^{4}$ As of July 7, 2015, a total of 18,338 responses had been collected (6106 for water sounds, 6207 for $25 \%$ sugar solution sounds, 6025 for 50 \% sugar solution sounds). The viscosity ratings for water $(\mathrm{M}=2.58, \mathrm{SD}=$ 1.62), $25 \%$ solution $(\mathrm{M}=2.66, \mathrm{SD}=1.46)$, and $50 \%$ $(\mathrm{M}=2.50, \mathrm{SD}=1.67)$ were significantly different from chance according to an independent samples KruskalWallis test $(p<.0005)$. Similarly, the liking ratings for 
water $(M=3.36, S D=1.76), 25 \%$ solution $(M=3.63$, $\mathrm{SD}=1.70)$, and $50 \%$ solution $(\mathrm{M}=3.66, \mathrm{SD}=1.67)$ were also significantly different from chance according to the Kruskal-Wallis test $(p<.0005)$.

${ }^{5}$ The entire study consisted of seven groups of questions. The participants were randomly assigned one question from each group. After they had answered these questions, they needed to explicitly click "continue" in order to get more questions (there are around 50 questions in total). As all three viscosity questions were in the same question group, the participants would have needed to be very persistent in order to have answered all of the viscosity questions.

${ }^{6}$ One might worry here about the effect of blindfolding on participants' judgments. However, to date, researchers have not observed a significant effect of blindfolding on people's loudness, pitch, or duration judgments, at least not when it comes to their evaluation of food eating sounds [68].

${ }^{7}$ That the blind can successfully fill vessels with liquid based on the sonic cues that are given off has been known about for some time. For instance, in his "Letter on the Blind" of 1749, Diderot anecdotally noted that "The blind man of Puiseaux . . . judges the fullness of vessels by the sound of the decanting liquid." ([69], p. 36; see also [70]).

${ }^{8} \mathrm{~A}$ chi-square goodness of fit test revealed participant's answers are almost significantly different from chance for both the sound of water poured into the white wine glass $\left(X^{2}(1,70)=3.66, p=.056\right)$ and into the red wine glass $\left(X^{2}(1,70)=2.80, p=.094\right)$.

${ }^{9}$ The participants might have performed a little better if they had listened to the sound of wine being poured into the respective glasses rather than water.

${ }^{10}$ As a further step, it is perhaps worth pausing to consider whether such anticipatory salivation might not also impact on the consumer's taste experience, at least their first taste (especially important given its role in anchoring the subsequent tasting experience; [71]).

${ }^{11}$ The oft-cited McGurk effect provides a particularly powerful demonstration of this phenomenon. Simply changing the lip movements, a person sees can predictably change the particular speech sounds that they hear a person speaking.

${ }^{12}$ Though, for those in the UK who would like to listen to and contemplate the possibly distinctive sound of their beer, perhaps, they should head for one of the specially identified quiet pubs [72].

${ }^{13}$ The equalization (EQ) of the hotter sound was increased around $200 \mathrm{~Hz}$ and decreased around $5-6 \mathrm{kHz}$, and vice versa for the colder sound.

${ }^{14}$ Perhaps, the ultimate accolade for distinctive signature packaging sounds is that they get taken up and incorporated as one of the instruments in music, as have happened with the Pringles pop and the sound of the Heinz Ketchup bottle [18].

${ }^{15}$ The following quote from Rachel Lewis, a strategist at iProspect in Texas is very much on-message here: "So while a user cannot taste the Champagne digitally, he or she can make a physical and sentimental connection to the brand via sound." (quoted in [58]; cf. [9]).

${ }^{16}$ As Johnnie Walker's brand director put it, when describing the musical glass: "This could potentially be a revolution within a culture that hasn't changed in decades. The glass is set to give drinkers a glimpse of what bar culture could be like in the future" ([59]).

${ }^{17}$ In this case, though, both attempts were ultimately unsuccessful.

\section{Competing interests}

The authors declare that they have no competing interests.

\section{Authors' contributions}

CS and QW both contributed to the writing of this paper. Data collection was performed by CS and QW. Statistical analysis was performed by QW. Both authors read and approved the final version of the manuscript.

\section{Acknowledgements}

The authors would like to thank Cormac Neeson from Crown Packaging for the discussion on the theme of auditory packaging design. CS would like to acknowledge the AHRC Rethinking the Senses grant (AH/L007053/1). Written informed consent was obtained for the publication of this manuscript and accompanying images.

Received: 14 July 2015 Accepted: 30 November 2015 Published online: 18 December 2015

\section{References}

1. Piqueras-Fiszman B, Spence C. Sensory expectations based on productextrinsic food cues: an interdisciplinary review of the empirical evidence and theoretical accounts. Food Qual Prefer. 2015;40:165-79.

2. Atlas LY, Wager TD. Expectancies and beliefs: insights from cognitive neuroscience. In: Ochsner KN, Kosslyn S, editors. The Oxford handbook of cognitive neuroscience, Volume 2: The cutting edges. Oxford: Oxford University Press; 2013. p. 359-81.

3. Spence C. Auditory contributions to flavour perception and feeding behaviour. Physiol Behav. 2012;107:505-15.

4. Hultén B, Broweus N, van Dijk M. Sensory marketing. Basingstoke: Palgrave Macmillan; 2009

5. Krishna A. Sensory marketing: research on the sensuality of products. London: Routledge; 2010

6. Krishna A. Customer sense: how the 5 senses influence buying behaviour. New York: Palgrave Macmillan; 2013.

7. Lindstrom M. Brand sense: how to build brands through touch, taste, smell, sight and sound. London: Kogan Page; 2005.

8. Spinney L. Selling sensation: the new marketing territory. New Scientist 2013;2934 (18th September).

9. Neff J: Product scents hide absence of true innovation. Advertising Age 2000;February 21:22. Downloaded from http://adage.com/article/news/ product-scents-hide-absence-true-innovation/59353/ 28/11/2012.

10. Gobé M. Emotional branding: the new paradigm for connecting brands to people. New York: Allworth; 2001

11. Hultén B. Sensory marketing: the multi-sensory brand-experience concept. Eur Bus Rev. 2011;23:256-73.

12. Krishna A. An integrative review of sensory marketing: engaging the senses to affect perception, judgment and behavior. J Cons Psychol. 2012;22:332-51.

13. Jackson DM. Sonic branding. London: Palgrave Macmillan; 2003.

14. Steiner P. Sonic branding. Berlin: Springer; 2014.

15. Treasure J. Sound business. Cirencester: Management Books 2000; 2007.

16. Byron E: The search for sweet sounds that sell: household products' clicks and hums are no accident; light piano music when the dishwasher is done? 
The Wall Street J 2012;October 23. Downloaded from http://www.wsj.com/ articles/SB10001424052970203406404578074671598804116

17. Özcan E. Product sounds: fundamentals and application. The Netherlands: PhD thesis, Delft Industrial Design; 2008

18. Spence C. Multisensory advertising \& design. In: Flath B, Klein E, editors. Advertising and design. Interdisciplinary perspectives on a cultural field. Bielefeld: Verlag; 2014. p. 15-27.

19. Spence C, Zampini M. Auditory contributions to multisensory product perception. Acta Acustica unit Acustica. 2006;92:1009-25.

20. Van Egmond R. The experience of product sounds. In: Schifferstein HNJ Hekkert P, editors. Product experience. London: Elsevier; 2008. p. 69-89.

21. Wolkomir R. Decibel by decibel, reducing the din to a very dull roar. Smithsonian Mag. 1996;26(11):56-65.

22. Spence C. Measuring the impossible. In MINET Conference: measurement, sensation and cognition (pp. 53-61). Teddington: National Physical Laboratories; 2009

23. Spence C, Zampini M. Affective design: modulating the pleasantness and forcefulness of aerosol sprays by manipulating aerosol spraying sounds. CoDesign. 2007;3(Supplement 1):109-23.

24. Knöferle KM. Using customer insights to improve product sound design. Mark Rev St Gallen. 2012;29(2):47-53.

25. Knöferle KM, Sprott DE, Landwehr JR, Herrmann A: Crossmodal influences of acoustic product cues varying in auditory pleasantness on consumer taste perceptions. 2014.

26. Stuckey B. Taste what you're missing: the passionate eater's guide to why good food tastes good. London: Free Press; 2012.

27. Vranica S: Sun Chips bag to lose its crunch. The Wall Street J 2010;October 6. Downloaded from http://online.wsj.com/article/SB1000142405274870384 3804575534182403878708.html

28. Smith P: Watch your mouth: the sounds of snacking. Good 2011;27th August. Downloaded from http://magazine.good.is/articles/watch-yourmouth-the-sounds-of-snacking 02/08/2014.

29. Spence C, Shankar MU, Blumenthal H. F Bacci, D Melcher. In: Bacci F, Melcher D, editors. Art and the senses. Oxford: Oxford University Press; 2011. p. 207-38.

30. Stummerer S, Hablesreiter M. Food design XL. New York: Springer; 2010

31. Velasco C, Jones R, King $S$, Spence C. "Hot or cold?" On the informative value of auditory cues in the perception of the temperature of a beverage. In: Bronner K, Hirt R, Ringe C, editors. (((ABA))) Audio Branding Academy Yearbook 2012/2013. Baden-Baden: Nomos; 2013. p. 177-87.

32. Velasco C, Jones R, King $S$, Spence $C$. The sound of temperature: what information do pouring sounds convey concerning the temperature of a beverage. J Sens Stud. 2013;28:335-45.

33. Spence C, Piqueras-Fiszman B. The multisensory packaging of beverages. In: Kontominas MG, editor. Food packaging: Procedures, management and trends. Hauppauge: Nova Publishers; 2012. p. 187-233.

34. Parthasarathy S, Chhapgar AF. Sound absorption in liquids in relationship to their physical properties: viscosity and specific heats. Ann Phys. 1955;5:297-303.

35. Vickers Z. Sound perception and food quality. J Food Qual. 1991;14:87-96.

36. Lawless HT. Sensory combinations in the meal. In HL Meiselman (Ed.), dimensions of the meal-the science, culture, business, and art of eating (pp. 92-106). Gaithersburg: Aspen; 2000

37. Wang $Q(J)$, Spence $C$. Assessing the effect of musical congruency on wine tasting in a live performance setting. i-Perception. 2015;6(3):1-13.

38. Zampini $\mathrm{M}$, Spence $\mathrm{C}$. Modifying the multisensory perception of a carbonated beverage using auditory cues. Food Qual Prefer. 2005;16:632-41.

39. Gaver WW. What in the world we hear?: an ecological approach to auditory event perception. Ecol Psychol. 1993;5:1-29.

40. Smith BC, editor. Questions of taste: the philosophy of wine. Oxford: Oxford University Press; 2007

41. Antin C: What does wine sound like? Punch 2014, January 28th. Downloaded from http://punchdrink.com/articles/what-does-wine-soundlike/ on 06/08/2014.

42. Cabe PA, Pittenger JB. Human sensitivity to acoustic information from vesse filling. J Exp Psychol Hum Percept Perform. 2000;26:313-24.

43. Gibson JJ. The senses considered as perceptual systems. Boston: Houghton Mifflin; 1966.

44. Gibson JJ. The theory of affordances. In: Shaw R, Bransford J, editors. Perceiving, acting, and knowing. Hillsdale: Erlbaum; 1977. p. 67-82.

45. Gaver WW. How do we hear in the world?: explorations in ecological acoustics. Ecol Psychol. 1993;5:285-313.
46. Pavlov IP. Conditioned reflexes: an investigation of the physiological activity of the cerebral cortex. London: Oxford University Press; 1927 (Translated and Edited by GV Anrep).

47. Frolov YP. Fish who answer the telephone, and other studies in experimental biology. London: Kegan Paul; 1924. Trans. S. Graham (1937)

48. Spence C. Mouth-watering: the influence of environmental and cognitive factors on salivation and gustatory/flavour perception. J Texture Stud. 2011;42:157-71.

49. Gallace A, Ngo MK, Sulaitis J, Spence C. Multisensory presence in virtual reality: possibilities \& limitations. In: Ghinea G, Andres F, Gulliver S, editors. Multiple sensorial media advances and applications: New developments in MulSeMedia. Hershey: IGI Global; 2012. p. 1-40.

50. McGurk H, MacDonald J. Hearing lips and seeing voices. Nature. 1976;264:746-8.

51. Schifferstein HNJ, Spence C. Multisensory product experience. In: Schifferstein HNJ, Hekkert P, editors. Product experience. London: Elsevier; 2008. p. 133-61.

52. Spence $C$. Noise and its impact on the perception of food and drink Flavour. 2014;3:9

53. Engelen $\mathrm{H}$ : Sound design for consumer electronics. http://www.omroep.nl/ $\mathrm{nps} /$ radio/supplement/99/soundscapes/engelen.html (downloaded on 06-01-2006), 1999.

54. Flath B. Sound \& image. An experimental study on the influence of acoustical parameters on the perception of a product's image in TVcommercials. In: Bronner K, Hirt R, Ringe C, editors. Audio Branding Year Book 2010. Baden-Baden: Nomos; 2011. p. 229-38.

55. McMains A: How JWT Brazil and Dolby captured the iconic sound of Coke being poured over ice. Adweek 2015;May 21. Downloaded from http:// www.adweek.com/news/advertising-branding/how-jwt-brazil-and-dolbycaptured-iconic-sound-experience-coke-being-poured-over-ice-164920 on 08/07/2015

56. Lageat T, Czellar S, Laurent G. Engineering hedonic attributes to generate perceptions of luxury: consumer perception of an everyday sound. Market Lett. 2003:14:97-109.

57. Jordan PW. Designing pleasurable products: an introduction to the new human factors. London: Taylor \& Francis; 2000

58. Roberts K. Lovemarks: the future beyond brands. New York: Powerhouse Books; 2005

59. King J: Krug heightens sensory experience with listening device. Luxury Daily 2014;January 2nd. Downloaded from http://www.luxurydaily.com/ krug-heightens-sensory-experience-with-listening-device/ on 06/08/2014.

60. Baker N: Johnnie Walker reveals futuristic glass. The Drinks Business 2015 , 10th April. Downloaded from http://www.thedrinksbusiness.com/2015/04/ johnnie-walker-reveals-futuristic-glass/ on 02/07/2015.

61. Spence C, Piqueras-Fiszman B. The perfect meal: the multisensory science of food and dining. Oxford: Wiley-Blackwell; 2014

62. Howes D, Classen C. Ways of sensing: understanding the senses in society. London: Routledge; 2014

63. Anon. Psychology: the science of sensory marketing. Harvard Bus Rev. 2015: 93(3):28-29.

64. Ludden GDS, Schifferstein HNJ. Effects of visual-auditory incongruity on product expression and surprise. Int J Design. 2007;1:29-39.

65. Sapherstein MB: The trademark registrability of the Harley-Davidson roar: a multimedia analysis. http://www.bc.edu/bc_org/avp/law/st_org/iptf/articles/ content/1998101101.html\#fnB24, 1998

66. Wilde AD. Harley hopes to add Hog's roar to its menagerie of trademarks [Eastern Edition]. Wall Street J. 1995;23:B1.

67. El Akkad, O: Canadian court clears way to trademark sounds. The Globe and Mail 2012, 28th March. Downloaded from http://www.theglobeandmail. com/globe-investor/canadian-court-clears-way-to-trademark-sounds/ article4096387/ on 03/10/2015.

68. Dacremont C, Colas B. Effect of visual clues on evaluation of bite sounds of foodstuffs. Sci Aliment 1993:13:603-10.

69. Morgan M. Molyneux's question: vision, touch and the philosophy of perception. Cambridge: Cambridge University Press; 1977.

70. Tyndall J. The science of sound. New York: Philosophical Library; 1964. Original work published in 1875.

71. Woods AT, Poliakoff E, Lloyd DM, Dijksterhuis GB, Thomas A. Flavor expectation: the effects of assuming homogeneity on drink perception. Chemosens Percept. 2010;3:174-81.

72. Kogan P. Muzak-free London: a guide to eating and drinking and shopping in peace. London: Kogan Page; 1991. 